\title{
Influence of sociodemographic factors on treatment's choice for localized prostate cancer in Portugal
}

\author{
Mário Pereira-Lourenço, Duarte Vieira e Brito, João Pedro Peralta, Ricardo Godinho, Paulo Conceição, \\ Mário Reis, Carlos Rabaça, Amílcar Sismeiro \\ Urology Department Instituto Português de Oncologia Francisco Gentil, Coimbra, Portugal.
}

\begin{abstract}
Summary $\quad$ Introduction: Patients with localized prostate cancer ( $\mathrm{PCa}$ ) are active participants in the choice of treatment.

Objectives: To access the effects of social and demographic factors in the choice of treatment in cases of localized PCa, in a Portuguese population.

Methods: Identification of all patients with the diagnosis of localized PCa in the last four years in an oncological centre. Evaluation of the effects of sociodemographic factors (age, profession, literacy, marital status, district and number of inhabitants of the place of residence) in the choice of treatment. Results: 300 patients with localized PCa were evaluated: $17.3 \%(n=52)$ opted for radical prostatectomy $(R P) ; 39,3 \%$ had $(n=118)$ external radiotherapy; brachytherapy in $29.3 \%$ $(n=88)$ and other options (active surveillance, cryotherapy and hormonal therapy) in $14.1 \%(n=42)$. In relation to surgical treatment $(R P)$ the following results were obtained: $a)>70$ years: $3.9 \%(n=5)$; $\leq 70$ years: $27.5 \%(n=47), p<0.001$; b) primary sector: $10.3 \%(n=3)$; secondary sector: $16.2 \%$ $(n=27)$; tertiary sector: $24.1 \%(n=21)$; quaternary sector: $8.3 \%(n=1), p=0.296 ; c)$ marital status married: $17.9 \%$ $(n=47)$; single: $0 \%(n=0)$; divorced: $25.0 \%(n=5)$; widow: $0 \%(n=0), p=0.734 ; d)$ residency in a city: $14.1 \%(n=13)$; city > 4000 habitants: $22.7 \%(n=15)$; city $\leq 4000$ habitants: $16.9 \%(n=24), p=0.701$. Using multinomial regression with age $(p=0.001)$, district $(p=0.035)$, marital status $(p=0.027)$ and profession (0.179), this model explained $17.2 \%-28.4 \%$ of therapeutic choices $(p<0.001)$.

Conclusions: The main socioeconomical factor that influence treatment choice was age. Unmarried patients over 70 years choose less radical prostatectomy. Other sociodemographic factors have minor influence in the choice of the treatment.
\end{abstract}

KEY WORDS: Localized prostate cancer; Treatment; Sociodemographic factors; Portugal.

Submitted 19 September 2019; Accepted 13 November 2019

\section{INTRODUCTION}

Prostate cancer ( $\mathrm{PCa}$ ) is the second most common male cancer, accounting for $13.5 \%$ of all cancers diagnosed in the male population. The incidence is greater in developed countries, mostly due to the generalized use of Prostate Specific Antigen (PSA) (1). The use of PSA allowed for an increased number of diagnosed PCa, mostly increasing diagnosis of early stage PCa (localized disease), although the benefit on mortality is small and not altering the global mortality (2).

Patients with PCa, for prognostic and therapeutic effects are classified in low-risk, intermediate-risk and high-risk.
This classification utilizes PSA value, stage and histological grade by the Gleason Score or by the International Society of Urological Pathology (ISUP) classification (3). In low-risk patients, knowing that PCa behaves many times as an indolent cancer, therapeutic options are active surveillance (AS), radical prostatectomy (RP) or radiotherapy (RT), with focus on brachytherapy (BT) and external beam radiotherapy (EBRT) (3).

There are no differences in oncological results between the different options (4). However, high risk patients present with a significant risk of disease progression and death by $\mathrm{PCa}$, as such current guidelines recommend active treatment with RP with bilateral lymphadenectomy, EBRT plus 2 or 3 years of androgen deprivation therapy (ADT) or BT plus EBRT with or without ADT (3). Again, oncological results are similar between treatment options (4).

Treatment of localized PCa is paradigm of doctor and patient shared choice. The urologist must discuss with the patient the advantages and disadvantages of each treatment, its side effects and allow for the informed and conscious choice by the patient $(3,5)$. Notwithstanding all this recommendations, the agreement between the physician perception and patient preference is inferior to $40 \%$ (6). What motivates these patients with the same disease to choose different treatments? Is the patient ready for such a hard choice? This choice may be influenced by the beliefs and knowledge of the own patient (7). Patients that choose RP believe that this represents their best chance of cure and longevity, as all tumour is removed. Patients that opt for RT believe that it is a less invasive treatment, less painful and with less severe side effects (8-10). Literacy in health, defined by the ability to access, understand and use health related information various greatly among patients. Patients with lower levels of health literacy have a tendency for greater stress levels during the choice of treatment and receive different therapies (11).

It is necessary to understand that various sociodemographic factors influence the choice of treatment for localized PCa.

Various demographic, economic and social factors have been described and influencing factors such as age (7, 12-17), race (15-20), financial status (15, 16, 18, 19, 21), health financing by private insurance $(7,17,19$, 20), educational level (21), marriage status $(7,15,17)$, populational density of residence area $(15,16,22)$ or hospital where treatment is provided $(12,20)$. 
In Portugal there is a lack of data for the degree of influence that sociodemographic factors have in the choice of treatment for localized PCa. This work takes advantage of the fact that it was conducted in an Oncological Centre that treats patients from all the central region of Portugal, and has as main objective to access the sociodemographic factors that influence patient preference for surgical treatment (in detriment of other treatments) and to understand if there is any asymmetry in the access of different treatments from patients residing in rural areas.

\section{Methods}

\section{Study design and population}

A retrospective study identified all patients that were submitted to a first prostate biopsy in an oncology reference centre (Portuguese Institute Of Oncology of Coimbra) between January 2014 and December 2018. Patients with the diagnosis of localized PCa were selected.

The choice of treatment was accessed, particularly the option for surgical treatment. We excluded all the patients that did not receive a treatment with curative purpose.

Evaluated variables and data collection methodology

- Choice of treatment: RP (classic or laparoscopic), BT, EBRT and other options (patients clinical process).

- Clinical variables: initial PSA and ISUP classification in prostate biopsy (patients clinical process)

- Social variables: age at diagnosis, marital status, education and profession (patients clinical process). Regarding profession, we classified into four categories: primary sector (extracting and collecting of natural resources, such as farming, fishing, forestry and mining); secondary sector (processing of raw materials, such as manufacturing and construction industries); tertiary sector (services, such as retail, banking, insurance, transports, restaurants, etc.); quaternary sector (knowledge applicable to some business activity that usually involves the provision of services, such as information gathering, distribution and technology, research and development, vocational education, business consulting and strategic financial services).

- Demographic variables: number of inhabitants of area of residence (city, $\geq 4000$ inhabitants, $<4000$ inhabitants, accessed by consulting the demographic data of the census of 2011 by the National Institute of Statistic).

\section{Statistical analysis}

Univariate analysis utilizing the Mann-Whitney test. Multivariate analysis with multinomial regression.

The patients that choose RP were compared with patients that opted for other therapies (evaluated together). A value of $p \leq 0.05$ was considered significative.

The program SPSS v21 was utilized.

\section{RESULTS}

Population characteristics are summarized in Table 1. Of the 576 biopsied patients, 300 presented with the diagnosis of localized PCa.
Table 1.

Population characteristics.

\begin{tabular}{|c|c|}
\hline Number of biopsied patients & 576 \\
\hline Diagnosis of PCa & $60.0 \%(n=347)$ \\
\hline$\cdot$ - Localized PCa & $86.5 \%(n=300)$ \\
\hline \multicolumn{2}{|l|}{ Number of inhabitants } \\
\hline · City & $31.3 \%(n=181)$ \\
\hline$>4000$ & $22.1 \%(n=121)$ \\
\hline$\leq 4000$ & $46.5 \%(n=269$ \\
\hline \multicolumn{2}{|l|}{ Education level } \\
\hline · Primary school & $74.7 \%(n=432)$ \\
\hline High school & $19.2 \%(n=111)$ \\
\hline College & $5.4 \%(n=31)$ \\
\hline No data & $0.7 \%(n=4)$ \\
\hline \multicolumn{2}{|l|}{ Marital status } \\
\hline · Married & $87.5 \%(n=506)$ \\
\hline Single & $2.8 \%(n=16)$ \\
\hline Divorced & $6.4 \%(n=37)$ \\
\hline Widow & $2.8 \%(n=16)$ \\
\hline No data & $0.5 \%(n=3)$ \\
\hline \multicolumn{2}{|l|}{ Profession } \\
\hline · Primary sector & $8.1 \%(n=47)$ \\
\hline - Secondary sector & $54.9 \%(n=317)$ \\
\hline · Tertiary sector & $30.1 \%(n=174)$ \\
\hline - Quaternary sector & $5.7 \%(n=33)$ \\
\hline - No data & $1.2 \%(n=7)$ \\
\hline PSA (median) & $8.3 \mathrm{ng} / \mathrm{ml}$ \\
\hline$\cdot \leq 10 \mathrm{ng} / \mathrm{ml}$ & $60.3 \%(n=328)$ \\
\hline . > $10 \mathrm{ng} / \mathrm{ml}$ & $39.7 \%(n=216)$ \\
\hline
\end{tabular}

Analysing patient's treatment choice for localized PCa, 39.3\% ( $\mathrm{n}=118$ ) opted for EBRT, 29.3\% ( $\mathrm{n}=88)$ for BT, $17.3 \%$ for RP ( $=52)$ and $14.0 \%(n=42)$ opted for other treatments (20 patients opted for active surveillance, 9 patients opted for cryosurgery and 13 patients received hormonotherapy). Of note 9 of the RP were laparoscopic.

The effect of the variables studied (univariate analysis) in the choice of surgical treatment is summarized in Table 2. In univariate analysis, only age related with the choice of surgical treatment, as $27.5 \%$ of patients aged $\leq 70$ years opted for RP, in contrast with only $3.9 \%$ of patients over 70 years $(\mathrm{p}<0.001)$

To evaluate if sociodemographic influenced the choice of surgical treatment, an analysis was conducted utilizing multinomial regression with all the previously described variables, resulting the following statistical significance for variables: age $(p<0.001)$, profession $(p=0.044)$, marital status $(p=0.027)$. Another multimodal regression with only the variables that presented statistical significance [age $(\mathrm{p}<0.001)$, marital status $(\mathrm{p}=0.027)$ and profession (0.179)], produced a model that explains $17.2 \%$ to $28.4 \%$ of choices of surgical treatment $(\mathrm{p}<0.001)$.

\section{Discussion}

Treatment of localized PCa has been regarded as a model of "treatment sensible to patient choice", where the patients beliefs and knowledge, together with clinical data provided by the physician lead to a shared decision about therapeutic option, even in the absence of strong scientific evidence (23). Data from the most recent study 
Table 2.

The effect of socioeconomical variables in choice of treatment (univariate analysis). ${ }^{\star} P$ value obtained in comparison between radical prostatectomy vs other treatments all together.

\begin{tabular}{|c|c|c|c|c|c|}
\hline & RP & RT & BT & Other & $\mathrm{p}^{*}$ \\
\hline \multicolumn{6}{|l|}{ Number of inhabitants } \\
\hline · City & $14.1 \%(n=13)$ & $45.7 \%(n=42)$ & $25.0 \%(n=23)$ & $15.2 \%(n=14)$ & 0.071 \\
\hline$\cdot>4000$ & $22.7 \%(n=15)$ & $39.4 \%(n=26)$ & $28.8 \%(n=19)$ & $9.1 \%(n=6)$ & \\
\hline$\cdot \leq 4000$ & $16.9 \%(n=24)$ & $35.2 \%(n=50)$ & $32.4 \%(n=46)$ & $15.5 \%(n=22)$ & \\
\hline \multicolumn{6}{|l|}{ Education level } \\
\hline · Primary school & $17.3 \%(n=41)$ & $39.8 \%(n=94)$ & $27.1 \%(n=64)$ & $15.7 \%(n=37)$ & 0.850 \\
\hline · High school & $21.7 \%(n=10)$ & $41.3 \%(n=19)$ & $32.6 \%(n=15)$ & $4.3 \%(n=2)$ & \\
\hline · College & $8.3 \%(n=1)$ & $25.0 \%(n=3)$ & $50.0 \%(n=6)$ & $16.7 \%(n=2)$ & \\
\hline - No data & $0.0 \%(n=0)$ & $50.0 \%(n=2)$ & $25.0 \%(n=1)$ & $25.0 \%(n=1)$ & \\
\hline \multicolumn{6}{|l|}{ Marital status } \\
\hline · Married & $17.9 \%(n=47)$ & $39.5 \%(n=104)$ & $30.0 \%(n=79)$ & $12.5 \%(n=33)$ & 0.734 \\
\hline - Single & $0.0 \%(n=0)$ & $0.0 \%(n=0)$ & $50.0 \%(n=4)$ & $50.0 \%(n=4)$ & \\
\hline - Divorced & $25.0 \%(n=5)$ & $45.0 \%(n=9)$ & $25.0 \%(n=5)$ & $5.0 \%(n=1)$ & \\
\hline · Widow & $0.0 \%(n=0)$ & $55.6 \%(n=5)$ & $0.0 \%(n=0)$ & $44.4 \%(n=4)$ & \\
\hline \multicolumn{6}{|l|}{ - No data } \\
\hline \multicolumn{6}{|l|}{ Profession } \\
\hline - Primary sector & $10.3 \%(n=3)$ & $48.3 \%(n=14)$ & $24.1 \%(n=7)$ & $5.6 \%(n=5)$ & 0.296 \\
\hline - Secondary sector & $16.2 \%(n=27)$ & $41.3 \%(n=69)$ & $26.9 \%(n=45)$ & $15.6 \%(n=26)$ & \\
\hline · Tertiary sector & $24.1 \%(n=21)$ & $34.5 \%(n=30)$ & $32.2 \%(n=28)$ & $9.2 \%(n=8)$ & \\
\hline - Quaternary sector & $8.3 \%(n=1)$ & $25.0 \%(n=3)$ & $50.0 \%(n=6)$ & $16.7 \%(n=2)$ & \\
\hline - No data & $0.0 \%(n=0)$ & $50.0 \%(n=2)$ & $25.0 \%(n=1)$ & $25.0 \%(n=1)$ & \\
\hline \multicolumn{6}{|l|}{ PSA } \\
\hline$\cdot \leq 10 \mathrm{ng} / \mathrm{ml}$ & $18.6 \%(n=31)$ & $32.3 \%(n=54)$ & $39.5 \%(n=66)$ & $9.6 \%(n=16)$ & 0.956 \\
\hline$\cdot>10 \mathrm{ng} / \mathrm{ml}$ & $9.6 \%(n=16)$ & $35.5 \%(n=59)$ & $40.4 \%(n=67)$ & $14.5 \%(n=24)$ & \\
\hline - Unknown & $29.4 \%(n=5)$ & $29.4 \%(n=5)$ & $29.4 \%(n=5)$ & $11.8 \%(n=2)$ & \\
\hline \multicolumn{6}{|l|}{ ISUP } \\
\hline$\cdot \leq 3$ & $17.2 \%(n=45)$ & $34.9 \%(n=91)$ & $33.3 \%(n=87)$ & $14.6 \%(n=38)$ & 0.956 \\
\hline$\cdot>3$ & $18.4 \%(n=7)$ & $68.4 \%(n=26)$ & $2.6 \%(n=1)$ & $10.5 \%(n=4)$ & \\
\hline \multicolumn{6}{|l|}{ Age (median) } \\
\hline$\cdot \leq 70$ years & $27.5 \%(n=47)$ & $27.5 \%(n=47)$ & $38.6 \%(n=66)$ & $6.4 \%(n=11)$ & $<0.001$ \\
\hline . > 70 years & $3.9 \%(n=5)$ & $55.0 \%(n=71)$ & $17.1 \%(n=22)$ & $24.0 \%(n=31)$ & \\
\hline
\end{tabular}

cryotherapy or hormonotherapy. Poor acceptance of AS reflects the low tradition of our institution in applying AS protocols.

Furthermore, the majority of patients want to "get rid of" or "cure" the cancer by undergoing aggressive therapy, even with awareness of the potential for significant side effects.

Most men seem unaware of the uncertainty/controversies that aggressive treatment may not cure their cancer or improve their survival. Limited knowledge about AS is common, and few patients think of it as a viable option, rather, many men perceive it as "doing nothing" (24). We observed that 13 patients only received hormonotherapy, corresponding to treatment-indicated patients who refused invasive therapies.

Such an important choice promoted doubt in most patients.

A prospective study with psychological evaluation of patients during choice of treatment for PCa, determined that most men presented stress related to the choice and patients that present higher levels of doubt felt more negative about therapeutic choice.

However, stress related to treatment choice decreased progressively, independently of treatment cho-

ProtecT (Prostate Testing for Cancer and Treatment), showed that during a median follow-up of 10 years, patients with localized PCa treated with active surveillance, RT or RP presented with similar mortality rates. However, surgery and RT presented with a smaller incidence of disease progression and metastasis (4). Consequently, most patients are confronted with a choice of similarly effective treatments.

The oncological centre where this work was conducted, not only receives patients from a vast geographic area but offers a wide range of treatments for patients with $\mathrm{PCa}$, without logistical interference (such as different waiting times between options), allowing for a more accurate evaluation of sociodemographic factors. Comparing with other studies, our series presented with a small percentage of patients choosing surgical treatment (17.3\%), in contrast with a larger number of patients that choose RT techniques $(68.6 \%)(7,12,15-17,19,21)$. This fact can be due to the feeling of some patients that RT is less invasive, less painful nand causing fewer side effects on the short term particularly incontinence (8-10). Other factor can be related to the low availability of laparoscopic surgery, in theory less invasive and better accepted by the patient. We also observed a small number of patients choosing active surveillance (AS), which is why we decided to group these patients with those who chose sen (25). In something so subjective and dependent on the individual perception of each patient and communication skills, it is highly likely that sociodemographic factors could influence patient choice and their urologist. Gordon et al. (26) showed that $>50 \%$ Afro-Americans and 24\% of white American studied, understood their disease as "non aggressive", even after a diagnosis of high risk disease.

In our work, age was the only factor that individually influenced the choice of treatment, as patients over 70 years were virtually not subjected to RP (only 3.9\%).

The influence of age is in agreement with literature ( 7 , 12-17), although such a small number leaves a doubt if some patients were excluded from a valid treatment because of their age. It must be understood that an individual with a life expectancy superior to 10 years should receive the same treatment as a young patient (3). Camargo Cancela et al. showed in their work that men over 70 years opted 5 times less for curative treatment (PR or RT), being age the main factor in choice, even after adjusting for other clinical and socioeconomical factors (14). In relation to RP, it is likely that older patients do not have this option discussed as much with their urologist, most likely due to the fear of complication, morbidity and presence of other pathologies (27).

In a study about RT modalities, patients residing far 
away from the hospital opted for faster and more definitive treatments (28), although our study points in another direction.

Another demographic factor is the assessment of the number of inhabitants in the area of residence. In our work we did not find a significative relation, although Schymura et al. described that patients from more urban areas and urban-rural opted more for RP in relation to rural areas (15).

In our multinomial model, marital status also influenced treatment choice as surgery was chosen in greater number by married and divorced patients. Most studies report that married patients opt more for surgical treatment $(7,15,17,29)$. The effect that the partner has in the decision is uncertain. Some studies showed the role of support and gathering of information by wives for their husbands, although the final decision was left for the husband (30-32). The effect of personal relations and opinion of friends was studied in other works. Patients with friends that have chosen curative and invasive treatment have a easier time opting for similar options (32). Patients from cultures with strong family ties, tend to rely more on the option of family (33).

In our final statistical model, we also considered profession, although it did not present with relevance. Educational level also did not influence choice of treatment. Some previous studies showed that patients residing in areas with higher educational levels chose surgical treatment with greater ease $(15,21)$. More information concerning the effect of economic capacity in the choice of treatment exists in literature (something that we cannot directly relate from profession and education in Portugal). Patients with greater economic capacity opt more for surgical treatment $(15,16,21,34)$. Assessment of these results should be careful, as access to healthcare in the United States of America is very different from the European and Portuguese reality. With this in mind, patients with access to private health insurance tend to choose more surgical treatment or more aggressive treatments $(7,17,19,20)$. However, a British study also noted that patients with higher socioeconomical level (defined by education, profession, income) have a tendency for more aggressive treatments (35).

Although not the main focus of this work, we also evaluated (univariate analysis) the effect of PSA and ISUP on treatment choice and found no relationship. In theory, by including all risk groups for localized disease in the analysis, we could underestimate surgical treatment, as these patients have several less aggressive treatment options to choose. This data indicates that the patient may not understand the risk stratification and its influence in treatment options (36).

In our study we did not evaluate the variable urologist in the choice of treatment. Different physicians have different clinical opinion and also communicate differently. In a general way, men that chose surgery tend to refer that their urologists opinion was the most important factor in their decision $(16,17,37)$. All this process is complex and multifactorial. Younger individuals tend to consult various information sources and different doctors. Patients with more aggressive disease usually tend to follow in a more strict manure the clinical opinion of their doctor (5). Another important fact, is time allowed to the patient to get a decision. Patients with more time to decide felt more involved in their choice, allowing them for advice from other doctors and family and social network (5).

This work has some limitations, starting with the retrospective design. Some factors that can influence choice of treatment were not studied, such as race (not very relevant in the population studied) (15-20) and presence of comorbidities $(12,15)$. We also decided to compare surgical treatment in relation to other treatments all together, something that can limit the effect of variables between different types of RT or other options. We did not exclude patients with comorbidities, which can interfere in the surgical indication or represent a contraindication for surgery. Other limitation is the lack of information about patient preference, degree of understanding of multiple options, time allowed for decision and degree of satisfaction with the form.

\section{Conclusions}

The main socioeconomical factor that influence treatment choice was age. The choice for RP from patients over 70 years is residual. A model including the variables age, profession and marital status helped to explain in a significant way patients' therapeutic choice. Factors such as education and residence in rural areas did not seem to influence choice of treatment.

\section{REFERENCES}

1. Ferlay J, Colombet M, Soerjomataram I, et al. Estimating the global cancer incidence and mortality in 2018: GLOBOCAN sources and methods. Int J Cancer. 2019; 144:1941-53.

2. Ilic D, Djulbegovic M, Jung JH, et al. Prostate cancer screening with prostate-specific antigen (PSA) test: a systematic review and meta-analysis. BMJ. 2018; 362:k3519.

3. Mottet N, Bellmunt J, Bolla M, et al. EAU-ESTRO-SIOG Guidelines on Prostate Cancer. Part 1: Screening, diagnosis, and local treatment with curative intent. Eur Urol. 2017; 71:618-29.

4. Hamdy FC, Donovan JL, Lane JA, et al. 10-year outcomes after monitoring, surgery, or radiotherapy for localized prostate cancer. N Engl J Med. 2016; 375:1415-24.

5. Song L, Chen RC, Bensen JT, et al. Who makes the decision regarding the treatment of clinically localized prostate cancer--the patient or physician?: results from a population-based study. Cancer. 2013; 119:421-8.

6. Elkin EB, Kim SH, Casper ES, et al. Desire for information and involvement in treatment decisions: elderly cancer patients' preferences and their physicians' perceptions. J Clin Oncol. 2007; 25:5275-80.

7. Kan CK, Qureshi MM, Gupta A, et al. Risk factors involved in treatment delays and differences in treatment type for patients with prostate cancer by risk category in an academic safety net hospital. Adv Radiat Oncol. 2018; 3:181-9.

8. Gwede CK, Pow-Sang J, Seigne J, et al. Treatment decision-making strategies and influences in patients with localized prostate carcinoma. Cancer. 2005; 104:1381-90.

9. Hall JD, Boyd JC, Lippert MC, Theodorescu D. Why patients 
choose prostatectomy or brachytherapy for localized prostate cancer: results of a descriptive survey. Urology. 2003; 61:402-7.

10. Holmboe ES, Concato J. Treatment decisions for localized prostate cancer: asking men what's important. J Gen Intern Med. 2000; 15:694-701.

11. Seaton CL, Oliffe JL, Rice SM, et al. Health literacy among Canadian men experiencing prostate cancer. Health Promot Pract. 2019:1524839919827576.

12. Cooperberg MR, Broering JM, Carroll PR. Time trends and local variation in primary treatment of localized prostate cancer. J Clin Oncol. 2010; 28:1117-23.

13. Weller D, Pinnock C, Silagy C, et al. Prostate cancer testing in SA men: influence of sociodemographic factors, health beliefs and LUTS. Aust N Z J Public Health. 1998; 22 (3 Suppl):400-2.

14. de Camargo Cancela M, Comber H, Sharp L. Age remains the major predictor of curative treatment non-receipt for localised prostate cancer: a population-based study. Br J Cancer. 2013; 109:272-9

15. Schymura MJ, Kahn AR, German RR, et al. Factors associated with initial treatment and survival for clinically localized prostate cancer: results from the CDC-NPCR Patterns of Care Study (PoC1). BMC Cancer. 2010; 10:152.

16. des Bordes JKA, Lopez DS, Swartz MD, Volk RJ. Sociodemographic Disparities in Cure-Intended Treatment in Localized Prostate Cancer. J Racial Ethn Health Disparities. 2018; 5:104-10.

17. Wagner SE, Drake BF, Elder K, Hébert JR. Social and clinical predictors of prostate cancer treatment decisions among men in South Carolina. Cancer Causes Control. 2011; 22:1597-606.

18. Friedlander DF, Trinh QD, Krasnova A, et al. Racial disparity in delivering definitive therapy for intermediate/high-risk localized prostate cancer: the impact of facility features and socioeconomic characteristics. Eur Urol. 2017; pii: S0302-2838(17)30652-8.

19. Lichtensztajn DY, Leppert JT, Brooks JD, et al. Undertreatment of High-Risk Localized Prostate Cancer in the California Latino Population. J Natl Compr Canc Netw. 2018; 16:1353-60.

20. Mahal BA, Chen YW, Muralidhar V, et al. National sociodemographic disparities in the treatment of high-risk prostate cancer: Do academic cancer centers perform better than community cancer centers? Cancer. 2016; 122:3371-7.

21. Morris CR, Snipes KP, Schlag R, Wright WE. Sociodemographic factors associated with prostatectomy utilization and concordance with the physician data query for prostate cancer (United States). Cancer Causes Control. 1999; 10:503-11.

22. Cary C, Odisho AY, Cooperberg MR. Variation in prostate cancer treatment associated with population density of the county of residence. Prostate Cancer Prostatic Dis. 2016; 19:174-9.

23. O'Connor AM, Llewellyn-Thomas HA, Flood AB. Modifying unwarranted variations in health care: shared decision making using patient decision aids. Health Aff (Millwood). 2004; Suppl Variation:VAR63-72.

24. Xu J, Neale AV, Dailey RK, et al. Patient perspective on watchful waiting/active surveillance for localized prostate cancer. J Am Board Fam Med. 2012; 25:763-70.

25. Steginga SK, Occhipinti S, Gardiner RA, et al. Prospective study of men's psychological and decision-related adjustment after treatment for localized prostate cancer. Urology. 2004; 63:751-6.

26. Gordon BE, Basak R, Carpenter WR, et al. Factors influencing prostate cancer treatment decisions for African American and white men. Cancer. 2019; 125:1693-1700.

27. Hosain GM, Sanderson M, Du XL, et al. Raciallethnic differences in treatment discussed, preferred, and received for prostate cancer in a tri-ethnic population. Am J Mens Health. 2012; 6:24957 .

28. Mahal BA, Chen YW, Sethi RV, et al. Travel distance and stereotactic body radiotherapy for localized prostate cancer. Cancer. 2018; 124:1141-9.

29. Tyson MD, Andrews PE, Etzioni DA, et al. Marital status and prostate cancer outcomes. Can J Urol. 2013; 20:6702-6.

30. Srirangam SJ, Pearson E, Grose C, Bet al. Partner's influence on patient preference for treatment in early prostate cancer. BJU Int. 2003; 92:365-9.

31. Berry DL, Ellis WJ, Woods NF, et al. Treatment decision-making by men with localized prostate cancer: the influence of personal factors. Urol Oncol. 2003; 21:93-100.

32. Davison BJ, Oliffe JL, Pickles T, Mroz L. Factors influencing men undertaking active surveillance for the management of low-risk prostate cancer. Oncol Nurs Forum. 2009; 36:89-96.

33. Drake BF, Keane TE, Mosley CM, et al. Prostate cancer disparities in South Carolina: early detection, special programs, and descriptive epidemiology. J S C Med Assoc. 2006; 102:241-9.

34. Mettlin C, Murphy GP, Menck H. Trends in treatment of localized prostate cancer by radical prostatectomy: observations from the Commission on Cancer National Cancer Database, 1985-1990. Urology. 1994; 43:488-92.

35. Fairley L, Baker M, Whiteway J, et al. Trends in non-metastatic prostate cancer management in the Northern and Yorkshire region of England, 2000-2006. Br J Cancer. 2009; 101:1839-45.

36. Liu Q, Xu Z, Mao S, et al. Perineal lipoblastoma: a case report and review of literature. Int J Clin Exp Pathol. 2014; 7:3370-4.

37. Scherr KA, Fagerlin A, Hofer T, et al. Physician Recommendations Trump Patient Preferences in Prostate Cancer Treatment Decisions. Med Decis Making. 2017; 37:56-69.

\section{Correspondence}

Mário Pereira-Lourenço, MD (Corresponding Author) mariolourenco88@gmail.com

Duarte Vieira e Brito, MD

duartevbrito@hotmail.com

Juan Pedro Peralta, MD

joaopedroperalta@gmail.com

Ricardo Godinho, MD

ricardogodinhoandrade@gmail.com

Paulo Conceição, MD

pjcconceicao@hotmail.com

Mario Reis, MD

reismario58@gmail.com

Carlos Rabaça, MD

carlosrabaca@gmail.com

Amilcar Sismeiro, MD

urosc2@ipocoimbra.min-saude.pt

Urology Department Instituto Português de Oncologia

Francisco Gentil, Coimbra

Rua Maria Bourbon Bobone, n57, RE/Esq, Coimbra, 3030-481, Portugal 